\title{
Role of E-Commerce in the Economic Development of Nigeria (Konga a case study)
}

\author{
Article by Vincent Audu Adejoh \\ Management, Texila American University, Nigeria \\ E-mail:vadejoh@gmail.com
}

\begin{abstract}
The main objective of the study is to investigate the impact of e-commerce on emerging market. The study aims at examine the role of electronic commerce in promoting the development of emerging online market firm. The study used a descriptive research design in gathering data from employee working in Konga. One Hundred and Twenty-Seven male and female employee working in this organization were involved in the study. The study participants were selected using convenience sampling techniques. The data gathered from the respondents were analyzed with both descriptive and inferential statistics. One hypothesis was tested using multiple regression analysis at $0.05 \%$ level of significant. The analysis reveals that e-commerce would significantly have influence $\left\{F(1,126)=25.270, R^{2}=.168, P<0.05\right\}$ on developing market of Konga online marketplace. In addition, the analysis shows that $16.8 \%$ variation in developing market of Konga online marketplace can be explained by the level of e-commerce adopted. E-commerce adoption strategies significantly improve the firm growth and development. It is recommended that more e-commerce promoting policy should be established to improve the level of ecommerce adoption in Nigeria. It is suggested that business firm should incorporate e-commerce related system to their business operation to boost the overall growth of Nigeria economy.
\end{abstract}

Keywords: Electronic Commerce, Development, Performance, ICT, Emerging Market, Growth.

\section{Introduction}

In recent time, there has been a great shift in literature among scholars concerning the use of Information and Communication Technologies (ICT) towards economic growth and development (Javier, et al., 2011). However, E-commerce is defined by Tito (2014) as business carried out over the Internet. It could be purchasing or selling, or a mix of both. It could be product, service or a mix of both. E-Commerce is an improvement which has developed in parallel to the development of communication and computer technologies. It has the potential and capabilities for revolutionizing the whole structure of retail selling and shopping (Ikemelu, 2012). Despite the fact that it is a new concept, it does not just suggest an alternative to the conventional commerce. The potential benefits and importance derived from the adoption of ICT in businesses have been pointed out in a wide variety of contexts, including commerce, health, education to mention only but few. Many business practices have been altered due rapid development and popularity of information technology. Konga (http://www.konga.com/) and similar e-commerce websites, where customers buy products and pay for them on the Web, have grown rapidly and become a critical channel for reaching consumers which then affect positively the economic development of Nigeria.

Konga is a Nigerian electronic commerce organization founded in 2012 with headquarters in Ikeja, Lagos State. It offers an outsider online marketplace, and also first-party direct retail spreading over different categories including consumer electronics, fashion, home appliances, books, children's items, and personal care products. Konga was founded in July 2012 by Sim Shagaya, with 20 staff (FinancialTimes, 2015). Generally, Konga Nigeria is likewise one of the today's Nigerian one-stop online retail shops offering a wide selection of products including Mobile Phones, Computers, Electronics, Home Appliances, Toys, Books, Wears and numerous more similarly as Jumia, conveying them ideal to customers' doorstep. Konga is an indirect competitor to Jumia in four categories and currently only delivers to Lagos. It likewise offers a wide selection of styles and brands, $100 \%$ convenience with every minute of every day online access from home or office, secure payment, for example, Bank Deposit/Online banking and Cash on Delivery, exceptional customer care service, Fast next-day or a 
few days delivery and parcels more. Konga can additionally be followed up via web-based networking media like Facebook, Twitter, and Youtube.

As promising and consistent as internet business shows up, there are several difficulties and challenges facing e-commerce as regards economic development. One element noted influencing the utilization of web based business for online shopping in Nigeria "is the absence of a broadly satisfactory and perceived installment strategy for online products and enterprises" (Ajayi et al., 2008). Ayo et al. (2008:4) sets that the low level of e-Payment framework in the nation, fills in as an obstruction to open support in online business. From past explores did on e-installment in Nigeria, it is obvious that the Automated Teller Machine (ATM) is the most unmistakable strategy for installment in Nigeria (Adeyeye, 2008; Ayo et al. 2008). Most people have no less than one bank ATM (money) card since they observe it to be an advantageous method for managing an account without queueing up in banks for money. On the other hand, Ayo et al., (2008:2) opines that, however the exploration and utilization of the ATM is generally acknowledged across the country, "it is just a method for making nearby installments and not for internet business services, for example, online shopping and this negatively affects online shopping in Nigeria. Deficiency of indigenous online sellers is likewise another critical calculate influencing online shopping Nigeria Adeyeye (2008:1).

The vast majority who shop online do as such from outside online merchants like Amazon and eBay in light of the fact that there are not very many tenable online sellers in Nigeria. Be that as it may, shopping from these remote sellers can be demoralize because of high delivering costs and most requests not being prepared. Nigeria, for a considerable length of time, had a negative notoriety as one of the world's most degenerate nations taking part in wide scale Internet falsification. A current review by the Internet Crime Complaint Center (IC3) positions Nigeria third on the planet with $8.0 \%$ of culprits of digital - wrongdoing living in Nigeria after the US (65.4\%) and UK (9.9\%) (Internet Crime Complaint Center, 2009). This rate when contrasted and the aggregate populace of Nigerians (i.e. more than 140 million individuals) represents an impressive danger to the Internet world. In this manner, most online sellers are careful when managing orders from Nigeria because of a paranoid fear of extortion and loss of cash. Thus, it is not astonishing that only a little part of the Nigerian masses participates in online shopping. A recent review demonstrates that "exclusive $16 \%$ of the example studied shop online and the most prominent installment techniques utilized as a part of Nigeria were the prepaid card framework and direct installment to vendors' accounts (Adeyeye, 2008:5).The prepaid card framework includes purchasing a card to use for online purposes like checking examination comes about, purchasing broadcast appointment or reestablishing membership to services; while some online sellers require coordinate installment into their ledgers for buys made online, in this manner affirmation of installment is likewise required before requests are completely handled. Be that as it may, this strategy can demonstrate baffling and ease back as clients need to make physical installments in banks.

In terms of its impact in promoting the emerging market economic growth and development, ecommerce exposes company's product to millions of consumers, this means that more market are created for the product and this in turn will increase sales and productivity of the producers. Ecommerce is a good development in the world of business; it is highly appreciated in term of its power to promote business through online transaction at anytime and anyplace. The power of e-commerce allows geophysical barriers to disappear, making all consumers and businesses on earth potential customers and suppliers. Thus, switching barriers and switching costs may shift.

Consumers have become increasingly sophisticated and demanding with the availability and abundance of products, services, information, technology, as well as retail stores and channels (Terblanche and Boshoff, 2004). Atuanya, Patrick, Augie \& Bala (2013) speaking from the consumer's viewpoint, obtaining value is a fundamental consumption goal and pivotal to all successful exchange transactions. In response, many retailers are seeking to turn shopping into a high-value pursuit and are highlighting consumer value as an important source of competitive advantage (Ayo, 2006). Despite the importance of value in creating consumer shopping experiences, existing literature on shopping value is limited. Researchers have conceptualized consumer shopping value from different perspectives and disagree upon dimensions of shopping value. Therefore, an in-depth understanding of consumer shopping value is needed. 
The role of e-commerce in promoting economic growth and development in Emerging market can be over-estimated. Without the e-commerce, creations of awareness about goods and services may not be possible and therefore company sales may be hampered and the detrimental effect of this is low productivity or inability of the firm to cover the cost of production. However, one of the challenges to e-commerce development in Nigeria may be in term of internet fraud where some people may collect credit information of consumers and use it as a means of duping them. This is a serious issue that makes some people to be skeptical of engaging in buying online especially in Nigeria where the issue of cybercrime is very serious. Cybercrime is a great threat to e-commerce in the world and specifically in Nigeria. Study on the role of e-commerce in promoting emerging market growth and development have not really attracted the attention of researchers because e-commerce is a new business techniques that is just gaining popularity among Nigerian. Many empirical findings have been carrying out in western world on e-commerce.

\section{Objectives of the study}

The study main objective is to investigate the role of e-commerce in promoting emerging market, the specifics objective is to investigate the relationship between e-commerce and emerging market growth in Nigeria.

\section{Methods}

The study will employ a descriptive survey research design. The study population consists of workers in Konga online shopping firm in Lagos. Employees in Konga have been purposively selected to represent workers population in online shopping industry. The sample of the study will consist of One Hundred and Twenty-Seven employees of Konga. Convenient sampling techniques will be employed in selecting sample. Respondents will be selected from their various departments in the organization. The participants will include both male and female. Questionnaire is the main instrument used for data collection. SPSS version 22 will be used to perform the descriptive and inferential statistics as applied to the research objectives.

\section{Testing of hypothesis}

\section{Descriptive statistics of socio-demographic characteristics of the respondents}

This section presents the analysis and interpretation of the personal information of the respondents. The personal information includes, sex of the respondents. The analysis and interpretations are presented below;

Table 1. Frequency and percentage distribution of respondents' sex

\begin{tabular}{lll}
\hline Response & Frequency & Percentage\% \\
\hline Male & 61 & 48.0 \\
Female & 66 & 52.0 \\
Total & 127 & 100.0 \\
\hline
\end{tabular}

The analysis table above reveals that male respondents account for 61(48.0\%) of the total respondents while female respondents account for 66(52.0\%) of the total respondents. Therefore, majority of the respondents $66(52.0 \%)$ are female.

Research Hypothesis: There will be no significant influence of e-commerce on developing market in Konga online marketplace.

To test the aforementioned hypothesis, a simple linear regression was conducted on the two variables to know if the independent variable would predict the dependent variable. The independent variable is e-commerce while dependent variable is developing market, the result of the analysis is given below; 
DOI: $10.21522 /$ TIJMG.2015.04.01.Art009

ISSN: $2520-310 \mathrm{X}$

Table 2. Simple linear regression analysis of market growth by E-commerce adoption

\begin{tabular}{|cl|l|l|l|l|l|l|}
\hline Model & & Sum of Squares & Df & Mean Square & F & $\mathrm{R}^{2}$ & p-val \\
\hline & Regression & 82.400 & 1 & 82.400 & & & \\
& Residual & 407.600 & 125 & 3.261 & 25.270 & .168 & .000 \\
& & & & & & \\
Total & 490.000 & 126 & & & & \\
\hline
\end{tabular}

Table 3. Simple linear regression coefficient

\begin{tabular}{llclll}
\hline Model & B & SE. B & Beta & T & P-Val \\
\hline $\begin{array}{l}\text { (Constant) } \\
\begin{array}{l}\text { E Commerce } \\
\text { adoption }\end{array}\end{array}$ & .166 & .855 & & 6.754 & .000 \\
\hline
\end{tabular}

$\left\{\mathrm{F}(1,126)=25.270, \mathrm{R}^{2}=.168, \mathrm{p}<0.05\right\}$.

The table above shows the prediction of e-commerce on the developing market of Konga online market place. The analysis reveals that e-commerce would significantly have influence $\{\boldsymbol{F}(\mathbf{1 , 1 2 6})$ $\left.=25.270, R^{2}=.168, P<0.05\right\}$ on developing market of Konga online marketplace. In addition, the analysis table shows that $16.8 \%$ variation in developing market of Konga online marketplace can be explained by the level of e-commerce adopted. Also, the analysis reveals that e-commerce as a variable independently influence developing market $(\boldsymbol{P}<.05, \boldsymbol{B}=\mathbf{4 1 0})$. Therefore null hypothesis is rejected and alternate hypothesis stands supported.

\section{Discussion of findings}

The study examines the impact of Ecommerce on developing market growth a case study of Konga Online Shopping Company. The hypothesis which states that there will be no significant influence of e-commerce on developing market in Nigeria was tested using simple linear regression analysis at $0.05 \%$ level of significant. In this study, e-commerce adoption was used as predictor variables while the developing market growth was used as an outcome variable. The findings show that adoption of ecommerce has significant impact on growth of Konga firm which may be in term of profitability, market shares, customer loyalty and competitive advantage. The findings show that e-commerce is a good trading strategy which tends to expose firm goods and service to a very large number of people and this tend to increase their sales and the level of profitability. When compare to the rival firms, an organization which adopt the use of online business are more likely to have better customers based and profit to their counterpart who are still operating traditional one on one business. Through e-commerce, firm ability to compete with their rival firms improves and their competitive advantage improves over time. As this was in line with the study of Atuanya, et al. (2013) who speaks from the consumer's viewpoint, that obtaining value is a fundamental consumption goal and pivotal to all successful exchange transactions. However, in response, many retailers are seeking to turn shopping into a highvalue pursuit and are highlighting consumer value as an important source of competitive advantage (McKnight, 2002).

\section{Conclusion}

The study findings have been able to successfully establish a significant impact of e-commerce on the growth of developing market such as Konga in Nigeria. The results so far suggest that e-commerce, even after being challenged by the cybercrime, is still a very important trading activity which can be adopted to boost the economy of the country. E-commerce increase buying and selling activities as individual does not necessarily need to see each other's before the business transaction can take place. Therefore, wider online marketing is created through e-commerce which will in turn be in overall advantage of economic growth and development. Based on results and findings, it is therefore 
concluded that e-commerce tends to improve the growth and development of developing market in Nigeria.

\section{References}

[1].Adeyeye, M. (2008). "E-Commerce, Business Methods and Evaluation of Payment Methods in Nigeria". Electronic Journal Information Systems Evaluation [Online], 11 (1), 1-6. http://www.ejise.com/volume11/volume11-issue1/Adeyeye.pdf.

[2].Ajayi, A. et al. (2008). "Improving the Response Time of Online Buyers in Nigeria: The Way Forward". Journal of Internet Banking and Commerce, 13 (1), 1-10.

[3].Atuanya, Patrick; Augie, Bala (6 December 2013). "Online Sales Boom as Konga, Jumia lure Shoppers". Business Day. Retrieved 24 December 2013.

[4].Ayo, C.K. (2006). "The Prospects of E-Commerce Implementation in Nigeria". Journal of Internet Banking and Commerce, 11 (3), 1-8.

[5].Gonca, T.Y., Eser, E.B., Bekir, Y \& Ozgur, S. (2014). E-commerce entrepreneurship and e-marketing in leather industry. Turkey: Ege University, Izmir. Retrieved from http://www.academia.edu on 05/07/2014.

[6].Ikemelu, C.R. (2012). Electronic commerce in Nigeria: concept and effective implementation. Journal of Research and Development, 4(1). December.

[7].Internet Crime Complaint Center. (2009), "Internet Crime Report". [Online]. http://www.ic3.gov/media/annualreport/2009_IC3Report.pdf.

[8]."Internet Sales Flourish in Nigeria". Financial Times. 14 May 2013. Retrieved 2 February 2015.

[9].Javier SL, Tractinsky N, Vitale M (2011). Consumer trust in an internet store. Inform. Technol. Manage., 1(12): 45-71.

[10]. "Konga's bold attempt to revolutionize online payments in Nigeria - Ventureburn". Ventureburn. Retrieved 2016-01-10.

[11]. McKnight, D.H. et al. (2002). "Developing and Validating Trust Measures for E-Commerce: An Integrative Typology". Information Systems Research, 13 (3), 334- 359.

[12]. Tito, P. (2014). Nigeria's e-commerce rises and the legitimate business opportunities it brings. Retrieved from www.naijapreneur.com on 28/09/2014. 